\title{
THE REFRACTION OF INDIAN SCHOOL CHILDREN*† A COMPARISON OF DATA FROM EAST AFRICA AND INDIA
}

\author{
BY
}

\author{
D. S. MCLAREN
}

East African Institute for Medical Research, Mwanza, Tanganyika

VERY little is known about the refractive state of populations in some of the technically underdeveloped countries of the world. What data there are from these parts have usually been collected in the course of an ophthalmic practice and are not representative of the population as a whole. Thorough studies have been made of very few groups, notably of palaenegrids by Holm (1937), Eskimos by Skeller (1954), and Indian children in Poona by Pendse (1954). The last report is of particular interest in that the refractions of two distinct social groups, the Brahmins and "untouchables", are compared and the possibility of environmental factors being responsible for the differences found is considered.

\section{Material}

The present report is of work undertaken as part of research being carried out in East Africa into the relationship of malnutrition and eye disease. The results of surveys in African children in Tanganyika have been published in full elsewhere (McLaren, 1960). Reference will be made here to the refraction findings in the African children where they have a bearing upon the data of Pendse and those of the Mwanza Indian children.

This would appear to be the first comparison that has been made of the refraction of two such communities of common origin living in different continents. The opening up of East Africa in the mid-19th century resulted in the movement into the interior, especially in connexion with the development of lines of rail and road communication, of Asiatics, both Arab and Indian. There are to-day quite large communities of Indians in all the towns of East Africa. The Asian population of Mwanza, estimated at 4 or 5,000, is made up largely of Hindus and Muslims, originally from Gujerat in Bombay Province, and of Sikhs from the Punjab. Only the children of Gujerat Hindus and Muslims attending the Indian Public Primary School, Mwanza, were included in the present study. No selection of children was made; all those present in a class at the time of examination were included.

\footnotetext{
* Received for publication November 2, 1960.

+ This investigation was supported in part by Research Grant No.: B-2190 from the National Institute of NeuroThis investigation was supported in part by Research Grant No.: B-2
logical Diseases and Blindness of the United States Public Health Service. 
As a general rule they were from middle-class families, with similar occupations, economic standards, and social habits to those of the Brahmin children of Pendse's study. They too were usually vegetarian but not strictly so. Like the Chitpavans and Deshasthas of Poona, the Patels, Lohanas, and Banias of Mwanza do not as a rule allow marriage outside the caste, and because of the smaller numbers of eligible young men and women available in East Africa recourse frequently has to be made to India itself. It would seem reasonable then to compare the Mwanza Indian data with those of Pendse's Brahmins of the "advanced community" in Poona.

\section{Methods}

Refraction was carried out using an electric retinoscope under complete cycloplegia produced by the repeated instillation of hyoscine hydrobromide drops (1/20 per cent.) as advocated by Sorsby, Sheridan, Noores, and Haythorne (1955). Values were recorded separately for the horizontal and the vertical meridians of each eye. The results obtained of visual acuity testing in African and Asian children have proved quite unreliable and no attempt was made to assess it in the present study. The heights and weights of the children were also obtained. The height was measured in bare feet and was correct to the nearest $\frac{1}{4}^{\prime \prime}$. The weight was taken with girls wearing a dress and knickers and boys wearing a shirt and shorts. One pound was allowed for these clothes. The total numbers examined were 194 boys and 165 girls.

The major difficulty encountered in the presentation of the results has been the lack of uniformity of the methods adopted to represent refractive data. Three questions arise in this connexion. Firstly, what correction or corrections shall be made to the values obtained by retinoscopy? Secondly, what method shall be followed to obtain a single figure to represent the refraction of an individual? Thirdly, where may the arbitrary boundary between the aberrations of emmetropia and axial ametropia best be set? On the first point it is understood that $1 \mathrm{D}$ is subtracted for the working distance of one metre, but a further subtraction of $1 \mathrm{D}$ for estimations under cycloplegia to compensate for the normal tone of the ciliary muscle (Duke-Elder, 1959) is not always followed. Confusion is worse confounded by those who do not state what corrections they have made. In my previous paper (McLaren, 1960), I made both these corrections and stated that I had done so. Pendse (1954) mentioned only the correction for distance, but in a personal communication he stated that he had not made the correction for cycloplegia and, therefore, as I mentioned in a footnote, there is a difference of $1 \mathrm{D}$ between my African data and Pendse's. In the present study I have applied only $1 \mathrm{D}$ correction to my data in order to bring them into line with his. 
The second problem, that of the means of expression of the refraction of an individual, is by its very nature almost insoluble in simple terms. No single figure can fully express the refractive state of a person who has gross differences between the two eyes, and between different meridians of the same eye. Pendse, following Sorsby (1928), took the lower hypermetropic axis as the determining factor, with the exception that the myopic axis was taken in cases of mixed astigmatism. It is not clear why this procedure was. followed, but in order to make comparison possible it was also used in the present study. In addition the mean of all four values obtained from the two horizontal and two vertical meridians of the two eyes was used for a separate calculation, as this seemed to be the simplest method and had been used for the African data. As will be seen later, there is practically no difference in the means calculated by the two methods.

The answer to the third question, regarding the limits of emmetropia and its aberrations, will naturally affect the entire analysis of group refraction data. Gardiner (1954) placed it at plus or minus $3 \mathrm{D}$ and this, together with his selection of material and his ignoring the retinoscopy findings and using the values for the glasses prescribed, makes it impossible to compare his study of London school children with Pendse's or mine. Pendse set the boundary at plus or minus $6 \mathrm{D}$ in conformity with general practice. However, Sorsby, Benjamin, Davey, Sheridan, and Tanner (1957) have recently brought forward good evidence for its being made at plus or minus $4 \mathrm{D}$ and this was followed previously (McLaren, 1960).

\section{Results}

In Figs 1 and 2 (opposite), the heights and weights of the Indian children living in Mwanza are compared with those of the children in the "advanced community" in Poona studied by Pendse. At all ages and for both sexes the Gujerati children of Mwanza exceed for both height and weight their fellow Marathas in Poona. This is rather surprising at first sight, for the latter were a notorious warrior race in the early days of British India whilst the Gujerats have always been puny and peace-loving by comparison. Pendse draws attention to the well-known difference in physical appearance between these two peoples. The explanation would seem to lie in the fact that nearly all the Mwanza children are of the second or third generation in East Africa. Their parents and grandparents made the break with their traditional surroundings and once they established themselves they rapidly prospered. The apparently unusually good physique of the Mwanza Indian children would seem to be at least in part an expression of their improved environment, especially as far as nutrition is concerned. Girls in both places and for both height and weight exceed boys from about 9-14 years of age in the usual manner. 


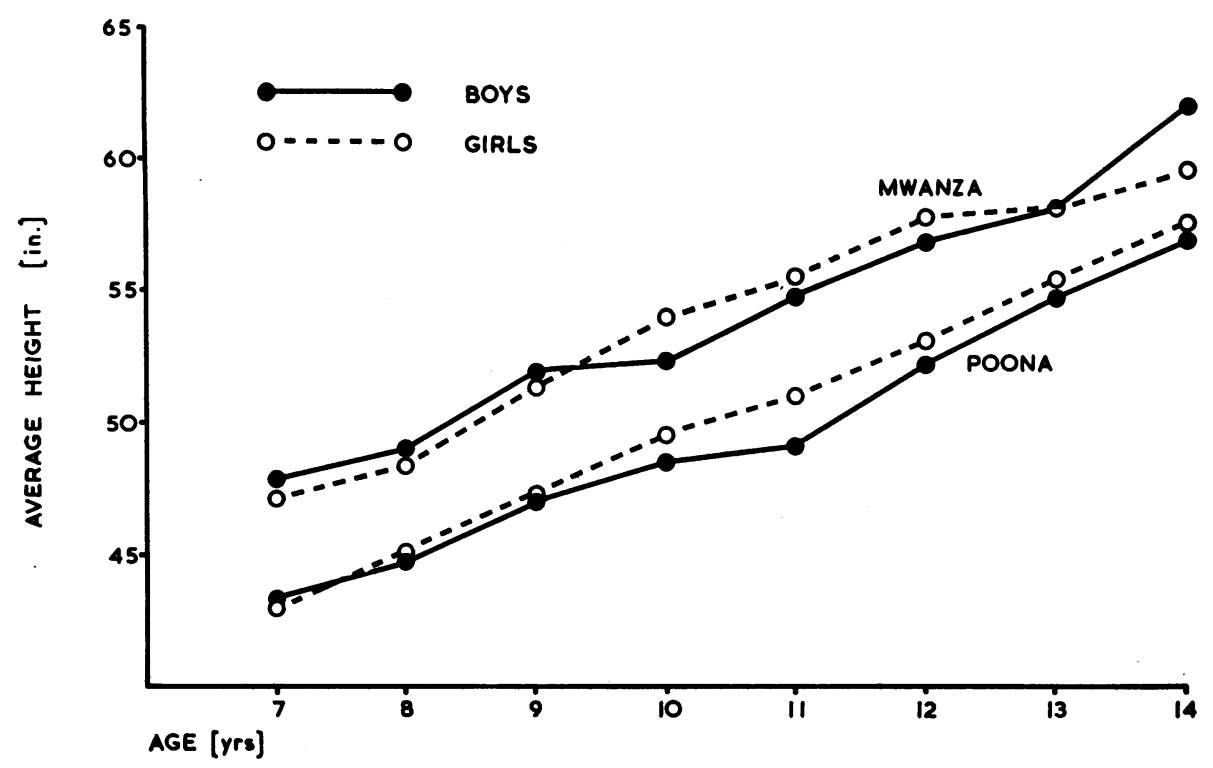

Fig. 1.-Mean heights of Mwanza and Poona boys and girls.

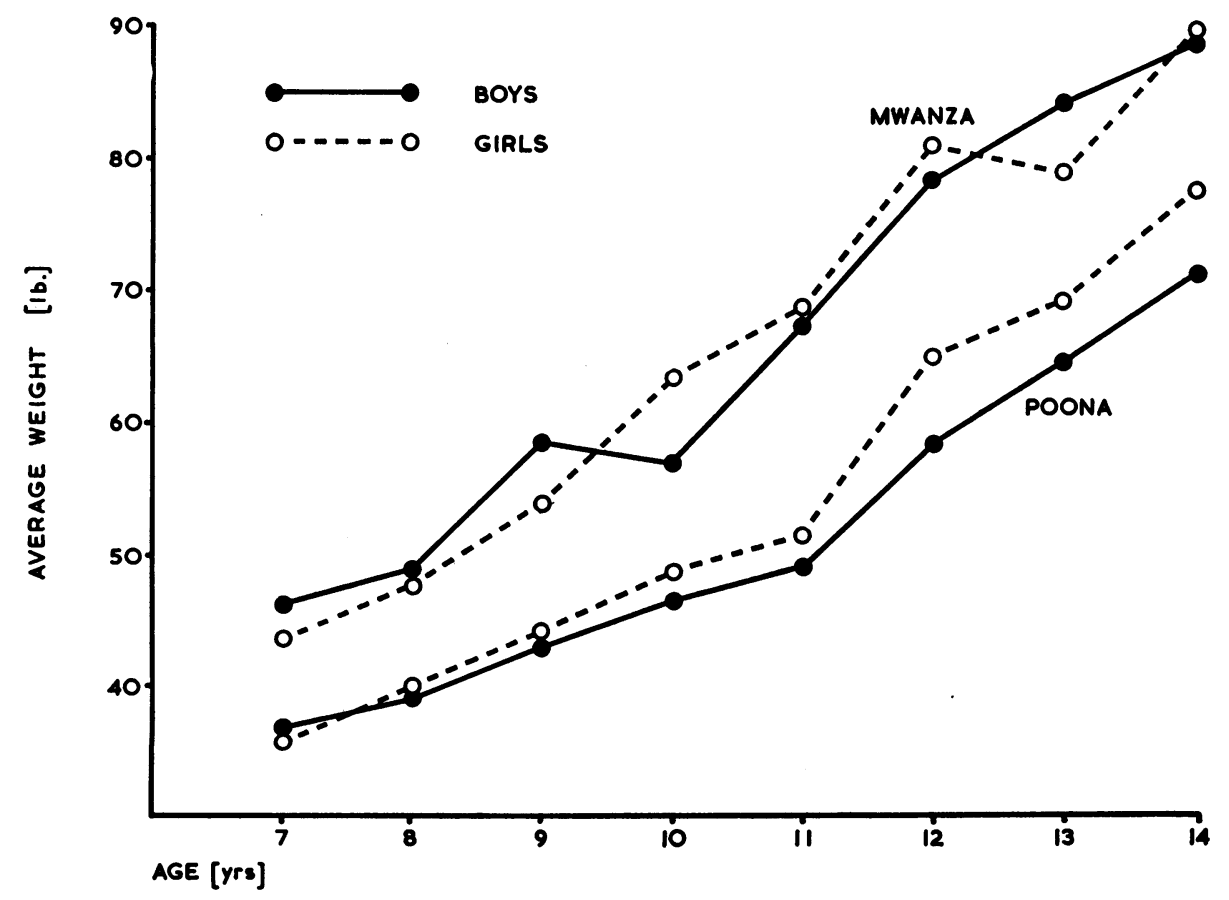

Fig. 2.-Mean weights of Mwanza and Poona boys and girls. 
The range of refraction in this series was from +5 to $-11 \mathrm{D}$. Approximately 86 per cent. of children showed ocular refractions between 0 and $+2 \mathrm{D}$, with only just over 2 per cent. with refraction greater than $+2 \mathrm{D}$ and of these only one case was above $+4 \mathrm{D}$. The remaining 11 per cent. or so were myopes with about 1 per cent. of the total due to myopes of over $-4 \mathrm{D}$. As would be expected, a higher proportion of the refractions of these children is in the range 0 to $+2 \mathrm{D}$ than is the case in the young men studied by Sorsby, Sheridan, Leary, and Benjamin (1960) and in other adult population studies quoted by him. There is, therefore, a myopic excess in these children and also a prolongation of the myopic tail, but the numbers, whilst large enough for other purposes, are perhaps rather small for showing the distribution and even several more hypermetropes would make a considerable difference. In the African children in Mwanza, there was an even higher proportion between 0 and $+2 \mathrm{D}$ with no myopic excess, whilst the highly abnormal findings at Mvumi showed a lowering of this proportion, due entirely to the gross excess of axial ametropes, of whom the majority were high myopes, thus producing a myopic excess and prolongation of the myopic tail in a different manner. Fig. 3 shows the marked excess of emmetropic and near-emmetropic refractions as compared with a normal distribution.

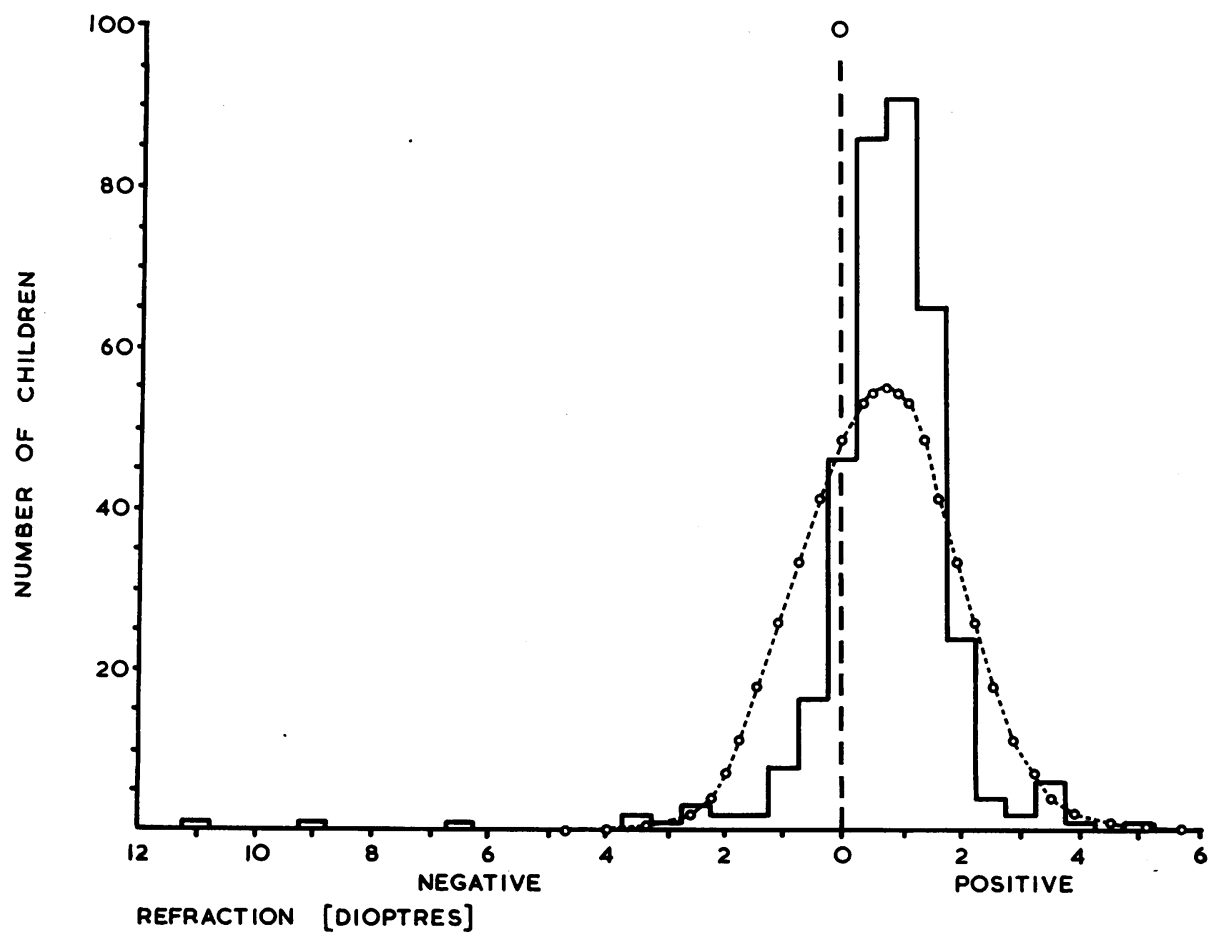

FIG. 3.-Refraction curve compared with normal distribution. 
In Fig. 4 the frequency distribution of refraction of children aged 6-12 years in Mwanza is compared with that of children of the same ages in Poona. The data given for the "advanced community" in Graph 6 of Pendse's monograph have been modified so that they appear on a percentage basis and so made suitable for comparison with the Mwanza data. The abscissa represents the refraction in dioptres divided into groups with an interval of $0.5 \mathrm{D}$. Thus the group numbered " 0 " includes mean refractions ranging from +0.25 to -0.24 and so on for the other groups. The close similarity between the curves for the children of the two places is evident.

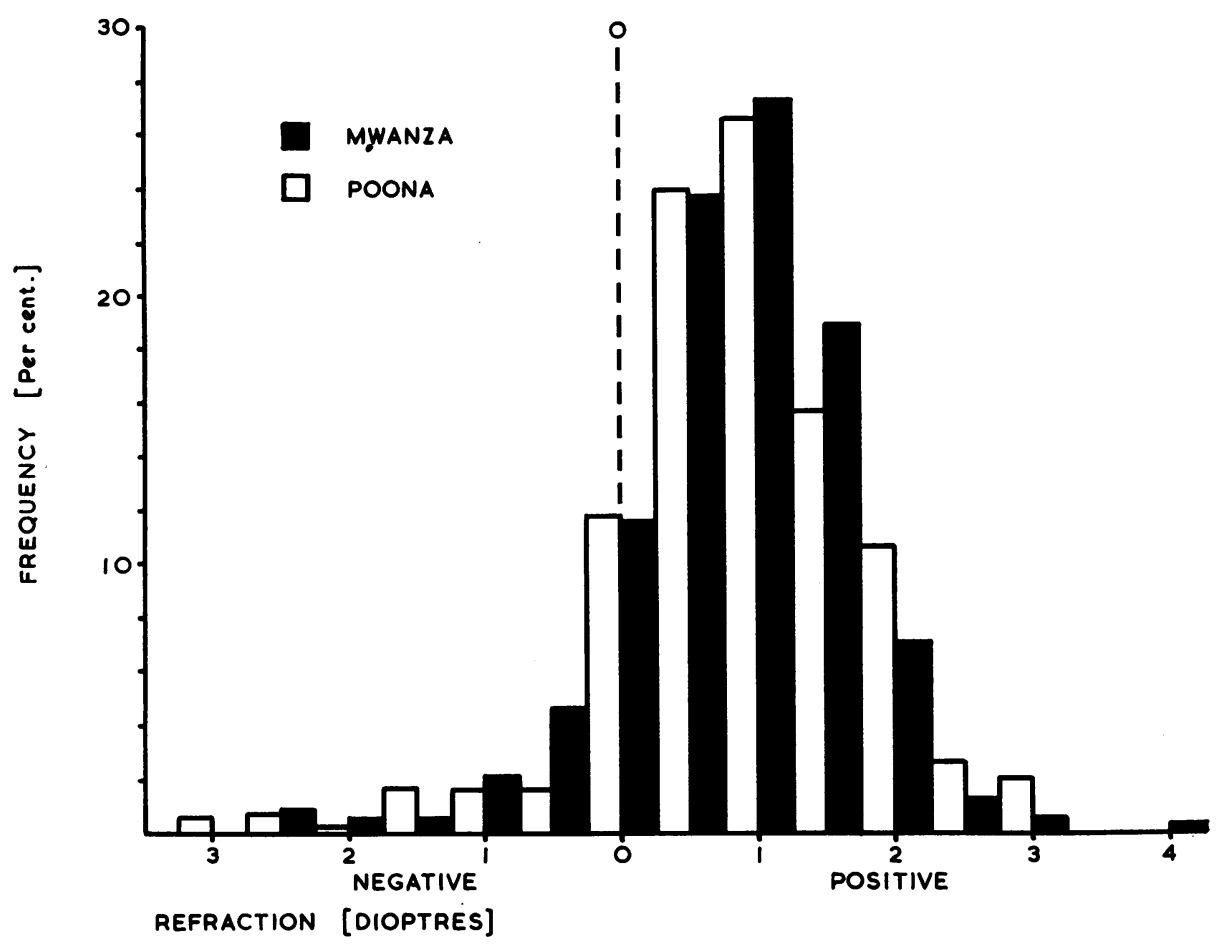

Fig. 4.-Frequency distribution of refraction.

It is a well-established fact that most babies are born hypermetropic and that with increasing age during childhood the refraction tends to approach emmetropia and in a small minority passes into myopia. Table I (overleaf) shows the mean refractions for the Mwanza Indian children separately by age and sex and also for the sexes combined. The refraction was calculated in two ways: (a) by the method of Sorsby (1928), and (b) by using half the sum of the mean values for each eye. Comparison of the mean refraction values calculated by these two methods shows that there is in all instances very little difference between them. As Pendse found with his data, there are no real 
TABLE I

MEAN REFRACTION OF MWANZA INDIAN CHILDREN (aged 6-14 yrs.)

\begin{tabular}{|c|c|c|c|c|c|c|}
\hline \multirow{2}{*}{ Sex } & \multirow{2}{*}{ Age (yrs) } & \multirow{2}{*}{ Number of Pupils } & \multicolumn{2}{|c|}{$\begin{array}{l}\text { Mean Refraction } \\
\text { (dioptres) }\end{array}$} & \multicolumn{2}{|c|}{$\begin{array}{c}\text { Standard Deviation } \\
\text { (dioptres) }\end{array}$} \\
\hline & & & (1) & (2) & (1) & (2) \\
\hline Male & $\begin{array}{r}6 \\
7 \\
8 \\
9 \\
10 \\
11 \\
12 \\
13 \\
14\end{array}$ & $\begin{array}{r}2 \\
15 \\
46 \\
25 \\
30 \\
38 \\
17 \\
11 \\
5\end{array}$ & $\begin{array}{l}+1.37 \\
+1.41 \\
+1.03 \\
+0.87 \\
+0.88 \\
+0.36 \\
+0.93 \\
+0.45 \\
-0.50\end{array}$ & $\begin{array}{l}+1.45 \\
+1.42 \\
+1.08 \\
+0.87 \\
+0.87 \\
+0.35 \\
+0.95 \\
+0.47 \\
-0.57\end{array}$ & $\begin{array}{l} \pm 0.17 \\
\pm 1.30 \\
\pm 0.63 \\
\pm 0.99 \\
\pm 0.83 \\
\pm 0.90 \\
\pm 0.59 \\
\pm 0.93 \\
\pm 1.55\end{array}$ & $\begin{array}{l} \pm 0.07 \\
\pm 1.40 \\
\pm 0.71 \\
\pm 1.43 \\
\pm 0.84 \\
\pm 1.00 \\
\pm 0.62 \\
\pm 0.89 \\
\pm 1.79\end{array}$ \\
\hline Female & $\begin{array}{r}6 \\
7 \\
8 \\
9 \\
10 \\
11 \\
12 \\
13 \\
14\end{array}$ & $\begin{array}{r}\overline{17} \\
38 \\
23 \\
30 \\
25 \\
20 \\
5 \\
5\end{array}$ & $\begin{array}{l}\overline{-} \\
+1.23 \\
+0.82 \\
+0.60 \\
+0.71 \\
+0.30 \\
+0.59 \\
+0.30 \\
+0.60\end{array}$ & $\begin{array}{l}\overline{0} \cdot 35 \\
+1.35 \\
+0.87 \\
+0.64 \\
+0.67 \\
+0.23 \\
+0.57 \\
+0.23 \\
+0.45\end{array}$ & $\begin{array}{l}\overline{-} \\
\pm 0.88 \\
\pm 0.90 \\
\pm 0.54 \\
\pm 1.12 \\
\pm 0.83 \\
\pm 0.64 \\
\pm 0.54 \\
\pm 0.60\end{array}$ & $\begin{array}{l}\overline{-} \\
\pm 0.85 \\
\pm 1.06 \\
\pm 0.62 \\
\pm 1.41 \\
\pm 0.94 \\
\pm 0.81 \\
\pm 0.81 \\
\pm 0.71\end{array}$ \\
\hline Both & $\begin{array}{r}6 \\
7 \\
8 \\
9 \\
10 \\
11 \\
12 \\
13 \\
14\end{array}$ & $\begin{array}{r}2 \\
32 \\
84 \\
48 \\
60 \\
63 \\
37 \\
16 \\
10\end{array}$ & $\begin{array}{l}+1.37 \\
+1.31 \\
+0.91 \\
+0.74 \\
+0.79 \\
+0.34 \\
+0.75 \\
+0.40 \\
+0.05\end{array}$ & $\begin{array}{l}+1.45 \\
+1.41 \\
+0.99 \\
+0.76 \\
+0.76 \\
+0.30 \\
+0.74 \\
+0.43 \\
-0.06\end{array}$ & $\begin{array}{l} \pm 0.17 \\
\pm 1.07 \\
\pm 0.77 \\
\pm 0.81 \\
\pm 1.01 \\
\pm 0.86 \\
\pm 0.64 \\
\pm 0.81 \\
\pm 1.19\end{array}$ & $\begin{array}{l} \pm 0.07 \\
\pm 1 \cdot 12 \\
\pm 0.90 \\
\pm 1 \cdot 10 \\
\pm 1 \cdot 16 \\
\pm 0.98 \\
\pm 0.62 \\
\pm 0.88 \\
\pm 1.27\end{array}$ \\
\hline
\end{tabular}

(1) Lower hypermetropic axis.

(2) Half the sum of means for each eye.

differences between the values for the two sexes. Consequently, in Fig. 5 (opposite), only the values for the sexes combined have been used, and in the case of those for Mwanza the close similarity of the values obtained by the two methods is demonstrated. The usual trend towards emmetropia with increasing age occurs in both groups and is probably more regular in Pendse's data because of his larger numbers.

It had been hoped to obtain more data on the possible relationship between axial myopia, or what Pendse calls extra-variational myopia, and growth. He found that the heights of his children over the age of 12 years with this high degree of error were significantly greater than the means of children of the same age and sex. However, the incidence of axial myopia seems to be considerably lower in the Mwanza children and only three had myopia of $-6 \mathrm{D}$ or more. Details of these cases are given in Table II. None showed degenerative changes. The heights and weights of these three children are below average. 


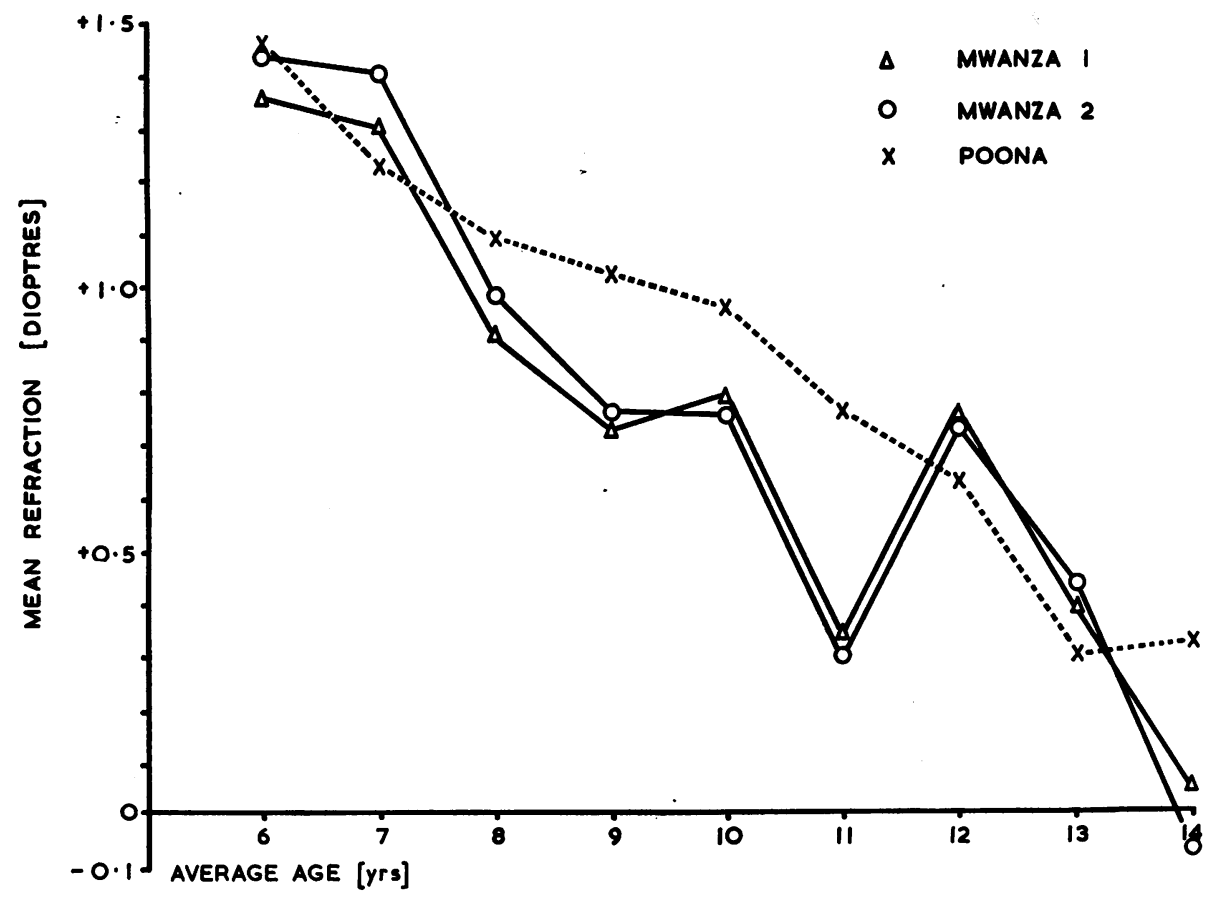

Fig. 5.-Change in mean refraction with age.

TABLE II

DETAILS OF CHILDREN WITH AXIAL MYOPIA

\begin{tabular}{|c|c|c|c|c|c|}
\hline Sex & Age (yrs) & Religion & Height (in.) & Weight (lb.) & $\begin{array}{c}\text { Refraction } \\
\text { (dioptres) }\end{array}$ \\
\hline $\begin{array}{l}\text { Male } \\
\text { Male } \\
\text { Female }\end{array}$ & $\begin{array}{l}11 \\
14 \\
10\end{array}$ & $\begin{array}{l}\text { Hindu } \\
\text { Hindu } \\
\text { Hindu }\end{array}$ & $\begin{array}{r}53(54 \cdot 6)^{*} \\
59(61 \cdot 8)^{*} \\
48 \frac{1}{4}(53 \cdot 8)^{*}\end{array}$ & $\begin{array}{r}55(66 \cdot 0)^{*} \\
71(88 \cdot 7)^{*} \\
48 \frac{1}{2}(63 \cdot 2)^{*}\end{array}$ & $\begin{array}{r}-6.5 \\
-11.0 \\
-9.0\end{array}$ \\
\hline
\end{tabular}

* Mean values in brackets.

Finally, the incidence of the conditions anisometropia and mixed astigmatism was sought. For the purpose of the present study, as in the previous work with Africans (McLaren, 1960), mixed astigmatism was regarded as present when $1 \mathrm{D}$ or more of difference occurred between the values for the vertical and the horizontal axes of the same eye. Anisometropia was taken as present when there was $1 \mathrm{D}$ or more difference between the two values for the same axis of the two eyes. Pendse did not examine his data in this way but in Table III (overleaf) the incidence of these conditions in the Mwanza Indian children is compared with that in the Mwanza and Mvumi African children. It will be seen that the Indian data have an intermediate position. About 10 per cent. of Sorsby's young men had astigmatism in excess of $1 \mathrm{D}$. 
TABLE III

INCIDENCE OF MIXED ASTIGMATISM AND ANISOMETROPIA IN TANGANYIKA (per cent.)

\begin{tabular}{l|c|c|c}
\hline \multirow{2}{*}{ Condition } & \multicolumn{2}{|c|}{ Mwanza } & Mvumi \\
\cline { 2 - 4 } & African & Indian & African \\
\hline Mixed Astigmatism & 1.8 & 6.6 & 12.9 \\
Anisometropia & 2.9 & 8.6 & 18.3 \\
\hline
\end{tabular}

The incidence of squint was about 1 per cent., i.e. four cases all convergent. Only three children, or less than 1 per cent., were wearing glasses at the time of examination, although it will be evident that many more require them.

\section{Summary}

The refraction and height and weight were measured of 359 unselected Indian school children residing in Mwanza. The data obtained were compared with those for a similar community of children in Poona.

The height and weight of Mwanza boys and girls exceeded at all ages those of their fellows in Poona. It is postulated that this is due to an improvement in the standard of living of the Indian community as a result of migrating to East Africa.

The range of refraction was from +5 to $-11 \mathrm{D}$. About 86 per cent. of children had refraction between 0 and $+2 \mathrm{D}$ and only 2 per cent. higher than $+2 \mathrm{D}$. The remaining 11 per cent. or so were myopes of whom only three or about 1 per cent. of the total were over $-4 \mathrm{D}$. These data show both a myopic excess and prolongation of the myopic tail. When compared with a normal distribution, there was a marked excess of emmetropic and nearemmetropic refractions.

There was close similarity between the frequency distribution of refraction of the Mwanza children aged 6 to 12 years and that of the Poona children of the same age.

Whether calculated by taking the lowest hypermetropic value or by halving the sum of the means for the two eyes, the Mwanza Indian data showed the normal trend towards myopia with increasing age in childhood.

The incidence of mixed astigmatism and anisometropia of $1 \mathrm{D}$ or more in degree was found to be 6.6 and 8.6 per cent. respectively.

About 1 per cent. of the children had squint. Less than 1 per cent. were wearing glasses at the time of examination, although many more required them.

This investigation was carried out with the permission of the Provincial Education Officer, Lake Province, and the co-operation of the Headmaster, Mr. M. M. Acharya and the staff of the Indian Public Primary School, Mwanza. My thanks are due to Dr. E. G. Holmes, Director, 
East African Institute for Medical Research for permission to publish and to Maurice Kwena for assistance with the refractions and Joseph Nyabuzoki for help with the data and the graphs.

\section{REFERENCES}

Duke-Elder, S. (1959). “Parsons' Diseases of the Eye", 13th ed., p. 77. Churchill, London. GARDINER, P. A. (1954). Lancet, 1, 476.

HoLM, S. (1937). Acta ophthal. (Kbh.), Suppl. 13.

MCLAREN, D. S. (1960). J. trop. Med. Hyg., 63, 101

Pendse, G. S. (1954). Indian med. Res. Mem., No. 38, "Refraction and Body-Growth".

SKelLeR, E. (1954). "Anthropological and Ophthalmological Studies on the Angmagssalik Eskimos". Lunos, Copenhagen.

SorsBY, A. (1928). Bull. Jewish Hlth Org., p. 1.

Benjamin, B., Davey, J. B., Sheridan, M., and Tanner, J. M. (1957). Spec. Rep. Ser. med. Res. Counc. Lond., No. 293.

Sheridan, M., Leary, G. A., and Benjamin, B. (1960). Brit. med. J., 1, 1394.

- _ - - MoOReS, N., and HAYTHORNe, J. (1955). Lancet, 2, 214. 